\title{
Variation among foliar isolates of Colletotrichum sublineolum of sorghum in Nigeria
}

\author{
P.S. Marley ${ }^{\mathrm{a},}$, R.P. Thakur ${ }^{\mathrm{b}}$, O. Ajayi ${ }^{\mathrm{a}}$ \\ anternational Crops Research Institute for the Semi-Arid and Tropics (ICRISAT), Kano, Nigeria \\ ${ }^{\mathrm{b}}$ International Crops Research Institute for Semi-Arid Tropics (ICRISAT), Patancheru, Andhra Pradesh 502324, India
}

Received 17 March 2000; received in revised form 14 September 2000; accepted 19 September 2000

\begin{abstract}
Foliar anthracnose, caused by Colletotrichum sublineolum, is a major disease of sorghum in Nigeria. Pathogenic diversity was studied among foliar isolates of $C$. sublineolum collected from sorghum cultivars in farmers fields in the Sahel, Sudan, northern Guinea and southern Guinea zones of Nigeria during the 1997 crop season. For the study a total of 50 isolates were identified based on typical symptom types and cultural characteristics. On the basis of growth in culture and morphological characteristics, the isolates were classified into nine morphological groups (MGs). Pathogenicity tests were done on a set of known sorghum differential lines by inoculating pot-grown seedlings in a greenhouse. On the basis of disease reaction and disease severity scores on the differential lines, the 50 isolates were classified into seven pathogenic groups (PGs). Sixteen representative isolates of the MGs and the PGs were further evaluated for virulence and aggressiveness on the differential lines and were classified into five distinct groups using the centroid method of cluster analysis. The existence of five races of C. sublineolum in major sorghum growing zones of Nigeria is suggested. (C) 2001 Elsevier Science B.V. All rights reserved.
\end{abstract}

Keywords: Sorghum bicolor; Colletotrichum sublineolum; Pathogenic variability; Nigeria

\section{Introduction}

Sorghum (Sorghum bicolor (L.) Moench) is an important cereal crop grown in the savanna zones of Nigeria between latitude $8^{\circ}$ and $14^{\circ} \mathrm{N}$, where it occupies about $40 \%$ of the total land area devoted to cereal production. The estimated current annual production is about $8 \mathrm{Tg}$ (NAERLS, 1996). Diseases constitute one of the most important constraints to sorghum production in Nigeria and other countries in

\footnotetext{
* Corresponding author. Present address: Faculty of Agriculture, Institute for Agricultural Research, Ahmadu Bello University, Samaru, Zaria, Nigeria.

E-mail address: psmarley@rcl.nig.com (P.S. Marley).
}

West and Central Africa (Thomas, 1995). Anthracnose, caused by Colletotrichum sublineolum Ces. causes serious damage (Tyagi, 1980) and infects all above ground parts of the plant. Peduncle, inflorescence and grain infection is referred to as panicle anthracnose and is now prevalent on farmer's fields (Marley, 1996a).

Foliar anthracnose is the most widely distributed foliar disease of sorghum in the Sahel, Sudan, northern Guinea and southern Guinea zones of Nigeria. It is particularly destructive in the northern Guinea and Sudanian zones (Pande et al., 1993) and has been reported to cause up to $47 \%$ yield loss at Samaru (Marley, 1996b) under experimental conditions. Foliar anthracnose is characterised by small sunken circular 
to elliptical spots 3-6 $\mathrm{mm}$ in diameter with few or numerous fruiting bodies (acervuli) of the fungus on leaf lesions (Tarr, 1962; Zummo, 1984). However, differences in symptomology are common and may be attributed to variability in the pathogen, host reaction, the physiological state of the host, and environmental conditions (Pastor-Corrales and Frederiksen, 1980; Ferreira et al., 1985; Pande et al., 1991). In Nigeria, three distinct types of symptoms have been identified: patchy and diffused spots on the lamina, commonly referred to as patchy; lesions and discoloration on the midrib, referred to as midrib; and isolated pinpoint spots on the lamina. Patchy and midrib symptoms are the most prevalent (Alawode et al., 1983; Manzo, 1985). Using symptom type as well as morphological, cultural and pathological characteristics, Alawode et al. (1983) identified a distinct variety of $C$. sublineolum as Colletotrichum graminicola var. isolatum. Further studies by Bindawa (1987) indicated the existence of only patchy and midrib lesions as symptoms and that pinpoint symptoms were initials of patchy symptoms that later became diffused. This study contradicted the report by Alawode et al. (1983) and questioned the establishment of C. graminicola var. isolatum as distinct from C. sublineolum.

However, earlier work by King and Frederiksen (1976) and Ozolua et al. (1986) had suggested the existence of races in C. sublineolum attacking sorghum leaves in Nigeria. These studies were limited by the number of isolates considered and the area covered during sample collection. Given the large area under cultivation, the diversity of genotypes used, and the need to verify conflicting earlier reports, further, more-detailed studies of anthracnose pathogen variation in Nigeria were needed. This paper reports pathogenic, cultural and morphological diversity among 50 foliar isolates of $C$. sublineolum collected from different locations in the Nigerian savanna.

\section{Materials and methods}

\subsection{Survey and sample collection}

Diseased leaf samples were collected during the 1997 crop season from major areas of sorghum production in the Sahel, Sudan, northern and southern Guinea savanna zones. Samples were also collected from some locations in the derived savanna within the forest zone where sorghum is sparingly cultivated. This was achieved by undertaking two main surveys as indicated on Fig. 1. The first survey route was from Ibadan-Zaria-Sokoto-Minna-Keffi-Enugu-LokojaAbuja to Zaria, and covered about $3344 \mathrm{~km}$. A total of 23 samples were collected. The second survey route from Zaria-Katsina-Kano-Nguru-Gashua-Damaturu-Maiduguri-Bama-Mubi-Yola-Jalingo-

Wukari-Langtang-Jos to Zaria, covered over $3595 \mathrm{~km}$ with 20 samples collected.

During the survey, stops were made every 100 $250 \mathrm{~km}$ and farmer's sorghum fields examined for symptoms of the disease. Stops were made every $50-100 \mathrm{~km}$ in areas where high cultivar diversity existed. At each stop, between one and five farmer's fields were inspected and diseased leaf pieces were cut, placed between blotter papers, labelled and packaged. They were then brought into the laboratory for examination. Samples were collected from one or more cultivars.

Seven samples were collected in Samaru and Bagauda, bringing the samples used in this study to 50 (Table 1). In general, sample collection emphasised cultivar diversity and collection from distinct zones in terms of temperature and rainfall conditions.

\subsection{Cultural and morphological variability}

From each leaf sample collected, diseased areas were cut into single-lesions and surface sterilised in $1 \%$ sodium hypochlorite solution for $1 \mathrm{~min}$. The diseased tissue was then rinsed in three changes of sterile distilled water, plated on freshly prepared oatmeal agar (OMA), and incubated at $28^{\circ} \mathrm{C}$ for 7 days under constant cool-white fluorescent light to induce abundant sporulation. Pure cultures raised from single spore of each isolate were identified and subcultured for use in this study. The isolates were studied for various traits, including sporulation potential, growth rate, and morphology of conidia and setae.

Sporulation potential was determined from spore counts taken using 7-day-old cultures of each isolate. A $10 \mathrm{~mm}$ diameter disk of each isolate was cut from the centre (oldest portion of each culture) with a sterile cork borer and placed in test tubes containing $10 \mathrm{ml}$ of sterile distilled water and shaken thoroughly to dislodge conidia. After filtering through a double-layered 


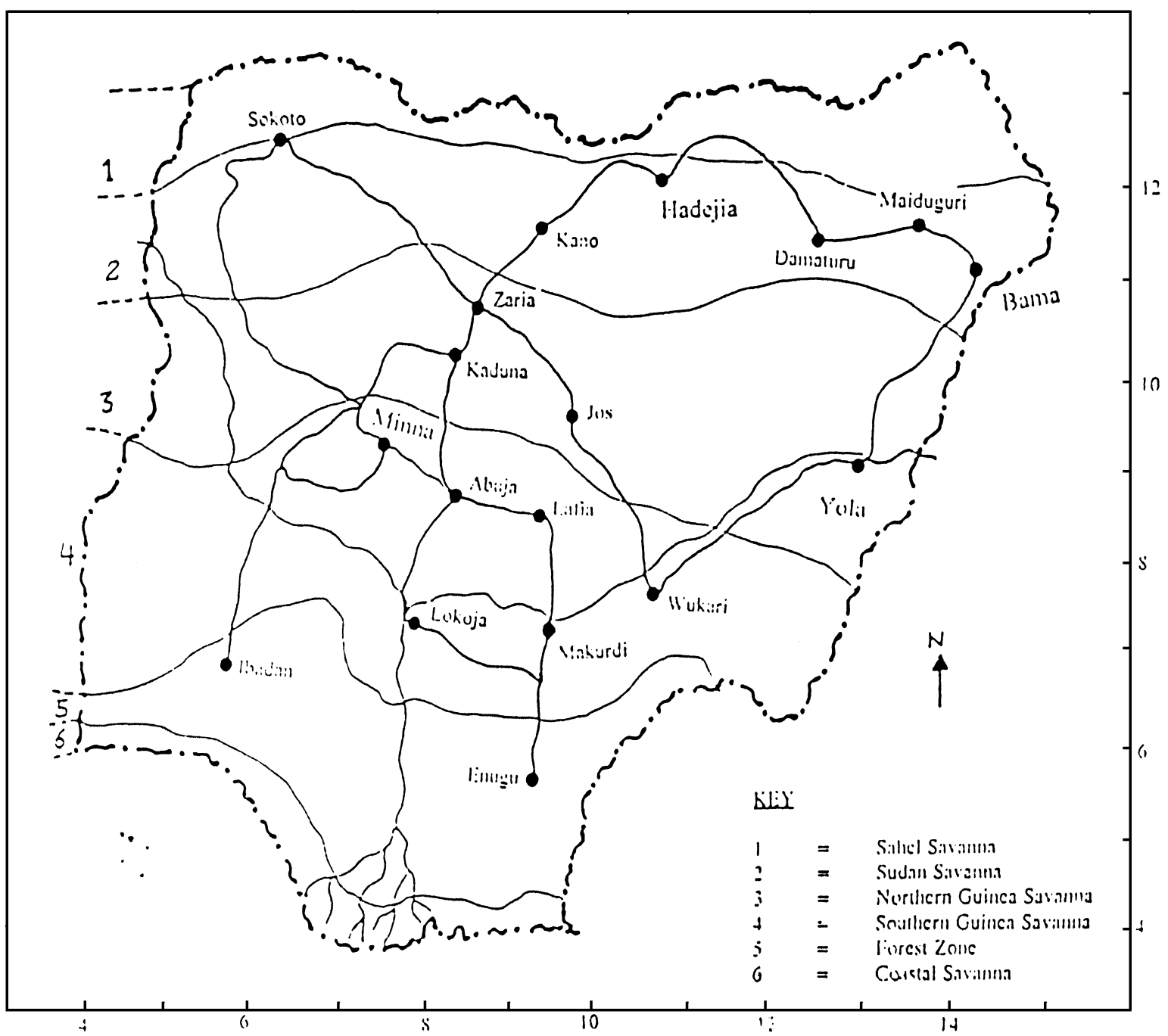

Fig. 1. Map of Nigeria showing the various routes of the survey in the five climatic zones where samples of Colletotrichum sublineolum were collected.

muslin cloth, spore and setae counts were taken using haemocytometer and the numbers of spores and setae per millilitre determined. Five replicate plates were used for each isolate.

Colony growth rate was measured by cutting $3 \mathrm{~mm}$ diameter disks of each isolate with a sterile cork borer, placing these onto OMA plates (care was taken to place the disks at the centre of the plates) and incubating as mentioned earlier. Seven days after inoculation, growth was measured and growth rate (mm per day) was calculated.
To record spore morphology; length and breadth of 50 spores of each isolate were measured using a stage micrometer/eye piece ocular scale and a compound microscope. Similarly, 50 setae obtained from each isolate were measured. For all the above studies five plates were maintained and each plate served as a replicate. Plates were arranged in a completely randomised design inside the incubator. The experiment was repeated once. The isolates were classified into different morphological groups (MGs) based on the above parameters. 
Table 1

Locations, designations and symptom types of foliar anthracnose samples collected from different sorghum types in Nigeria during the 1997 crop season

\begin{tabular}{|c|c|c|c|c|}
\hline Serial number & Location & Designation & Sorghum type/race & Symptom type ${ }^{a}$ \\
\hline 1 & Samaru & SM1 & Kaura (local) & Patchy \\
\hline 2 & Talata mafara & $\mathrm{TM}$ & BES & Patchy \\
\hline 3 & Sokoto & SK1 & BES & Patchy \\
\hline 4 & Dadin kowa & DK & Caudatum (local) & Patchy \\
\hline 5 & Kontogora & KT & Farafara (local) & Midrib \\
\hline 6 & Bokani & $\mathrm{BK}$ & Red guinea (local) & Pinpoint \\
\hline 7 & Ilorin1 & IL1 & White guinea (local) & Pinpoint \\
\hline 8 & Ibadan & IB & Red guinea (local) & Midrib \\
\hline 9 & Obbollo-affor & DA & Red guinea (local) & Midrib \\
\hline 10 & Makurdi & MK & Red guinea (local) & Midrib \\
\hline 11 & Bwari & BW & White guinea (local) & Patchy \\
\hline 12 & Nguru & NG & Dungoya (local) & Patchy \\
\hline 13 & Funtua & FT1 & Farafara (local) & Patchy \\
\hline 14 & Katsina & KT & ICSV III & Pinpoint \\
\hline 15 & Sabon rafi & SR & Yantsantawa (local kaura) & Midrib \\
\hline 16 & Damaturu & DMT1 & Tunkwushe local & Midrib \\
\hline 17 & Gezawa & GZ & Masakwa (post rainy season) & Pinpoint \\
\hline 18 & Damaturu & DMT2 & BES & Patchy \\
\hline 19 & Pulka gwoza & PGZ & Sambul (local white) & Pinpoint \\
\hline 20 & Fulka & PK & Masakwa (post rainy reason) & Pinpoint \\
\hline 21 & Damaturu & DMT3 & Yafimoro (local) & Patchy \\
\hline 22 & Bama & $\mathrm{BM}$ & Merekime (local) & Midrib \\
\hline 23 & Geidam & GD & Pramgram (kaura local) & Midrib \\
\hline 24 & Numan & NM & Local & Midrib \\
\hline 25 & Jalingo & JLG1 & Kashongong (local) & Pinpoint \\
\hline 26 & Amper & AP1 & Amper (local) & Midrib \\
\hline 27 & Pankshin & PK & Farafara (local) & Midrib \\
\hline 28 & Jalingo & JLG2 & Yarjingo (local) & Midrib \\
\hline 29 & Gu-wukari & GWK & Local & Midrib \\
\hline 30 & Langtang & LG & Local & Midrib \\
\hline 31 & Amper & AP2 & Trejen (local) (red) & Midrib \\
\hline 32 & Funtua & FT2 & SK 5912 & Patchy \\
\hline 33 & Gusau & GS & Farafara (local) & Midrib \\
\hline 34 & Samaru kataf & SKT & ICSV III & Patchy \\
\hline 35 & Buruku & BRK & Kaura (local) & Patchy \\
\hline 36 & Tegina & TG & Kaura (local) & Patchy \\
\hline 37 & Ikara & IK & Farafara (local) & Patchy \\
\hline 38 & Makarfi & $\mathrm{MKF}$ & Kaura (local) & Pinpoint \\
\hline 39 & Saminaka & SMK & Farafara (local) & Patchy \\
\hline 40 & Samaru & SM2 & ICSV 905 NG & Patchy \\
\hline 41 & Dangora & DG & BES & Pinpoint \\
\hline 42 & Ilorin & IL2 & Local & Patchy \\
\hline 43 & Sokoto & SK2 & Yarsafe (local) & Patchy \\
\hline 44 & Samaru & SM3 & ICSV III & Patchy \\
\hline 45 & Samaru & SM4 & ICSV 400 & Patchy \\
\hline 46 & Samaru & SM5 & Yarwasha (local) & Patchy \\
\hline 47 & Arika & $\mathrm{AK}$ & Farafara (local) & Midrib \\
\hline 48 & Bagauda & BG1 & Farafara (local) & Patchy \\
\hline 49 & Bagauda & BG2 & IRAT 204 & Patchy \\
\hline 50 & Bagauda & BG3 & ICSV 400 & Patchy \\
\hline
\end{tabular}

\footnotetext{
${ }^{a}$ Based on symptom description by Alawode et al. (1983) and Manzo (1985).
} 


\subsection{Pathogenicity test}

Eight sorghum lines (KVS 8, BES, IS 3758, IS 6926, IRAT 204, IS 6958, IS 18442 and A 2267-2) selected for known differences in response in the International Sorghum Anthracnose Virulence Nursery (ISAVN) coordinated by ICRISAT - Patancheru (Thakur, 1995) were used in pathogenicity testing. Each was grown from seeds sown in $30 \mathrm{~cm}$ diameter plastic pots filled with sterilised soil, with the pots arranged in the glasshouse in a randomised complete block design comprising 50 isolates of $C$. sublineolum (Table 1), eight test lines and five plants/pot (each plant served as a replicate). Leaves of 21-day-old plants were inoculated with spore suspension $\left(1 \times 10^{5}\right.$ spores $\left.\mathrm{ml}\right)$ of an isolate with a hand sprayer until runoff. Control plants were sprayed with sterile distilled water. Following inoculation, plants were maintained at high relative humidity $(>90 \%)$ for $12 \mathrm{~h}$ for two consecutive days at an average temperature of $28^{\circ} \mathrm{C}$. The isolates were classified into different pathogenic groups (PGs) based on their pathogenicity to specific sorghum lines.

\subsection{Assessment of virulence and aggressiveness}

Differences in virulence (the degree or measure of pathogenicity) amongst isolates was examined by comparing the number of genotypes on which isolates produced symptoms. The same eight sorghum lines were used in this study with plants grown and inoculated as described earlier. A total of 16 isolates, representing nine of the MGs and seven of the PGs were used. Inoculated plants were incubated in the greenhouse as described above and pots were arranged in a randomised complete block design. Each plant in a pot served as a replicate. The experiment was repeated twice.

Aggressiveness (ability to cause severe disease) among the isolates was measured by comparing the variation in the degree of pathogenicity (mean disease severity) on two lines (BES and IRAT 204), which were susceptible to all 16 groups of isolates.

\subsection{Disease scoring}

Two weeks after inoculation plants were rated for their reaction type as $\mathrm{R}, \mathrm{MR}$ or $\mathrm{S}$, where $\mathrm{R}$
$($ resistant $)=$ no symptoms, or presence of chlorotic flecks; MR (moderately resistant) = hypersensitive lesions, red spots or necrotic spots without acervuli; and $\mathrm{S}$ (susceptible) = lesions with acervuli.

Disease severity (percentage of leaf area covered by lesions) was recorded using the 1-9 visual rating where $1=$ no symptoms on leaf surface; $2=1-5 \%$; $3=6-10 \% ; 4=11-20 \% ; 5=21-30 \% ; 6=31-40 \%$; $7=41-50 \% ; 8=51-75 \% ; 9 \geq 75 \%$ of total leaf area of plant damaged by anthracnose.

\subsection{Data analysis}

Data were subjected to analysis of variance to determine significant differences among various treatments and their interactions. Disease severity data were subjected to cluster analysis using the centroid method on SPSS (Norman et al., 1984) to classify the isolates into different groups.

\section{Results}

\subsection{Survey and sample collection}

Geographic location, cultivar and symptom types of the samples used in the study are shown in Table 1.

\subsection{Morphological variability}

The 50 isolates were categorised into nine MGs on the basis of various growth and cultural characteristics (Table 2). The number of isolates identified in each MG varied; MGs 2, 5 and 9 had, respectively 9, 10 and 15 isolates, while MGs 6 and 8 had only one isolate each. Significant differences $(P<0.05)$ were found in all parameters evaluated (Table 3 ). MGs 2 and 3 had the highest growth rate of $4.3 \mathrm{~mm}$ per day. Conidia produced were falcate or spindle shaped, hyaline and aseptate. MG 9 produced conidia profusely with a spore count of $191.7 \mathrm{ml}^{-1}$ while MGs 4 and 6 had the lowest count of $41.7 \mathrm{ml}^{-1}$. MG 6 had the highest mean conidial length and width of 27.76 and $9.54 \mu \mathrm{m}$, respectively. The representative isolates selected from each of nine groups were: isolates $2,3,11,16,25,33,40$, 46 and 47. 
Table 2

Cultural and morphological grouping of 50 isolates of Colletotrichum sublineolum into cultural and morphological groups ${ }^{\mathrm{a}}$

\begin{tabular}{|c|c|c|c|}
\hline $\begin{array}{l}\text { Morphological } \\
\text { group }\end{array}$ & Isolate numbers & Isolate characteristics & $\begin{array}{l}\text { Representative } \\
\text { isolate selected }\end{array}$ \\
\hline MG 1 & $9,10,11,13(4)$ & $\begin{array}{l}\text { Dark brown colour with light tan top, most prominent } \\
\text { at middle of culture. Surface of culture with many } \\
\text { concentric rings with zonations which are very } \\
\text { prominent towards the middle }\end{array}$ & $11(\mathrm{P})^{\mathrm{b}}$ \\
\hline MG 2 & $4,7,14,15,16,19,24,26,29(9)$ & $\begin{array}{l}\text { Gray coloured cottony or fluffy cultures with only } \\
\text { one concentric ring close to point of inoculation }\end{array}$ & $16(\mathrm{M})$ \\
\hline MG 3 & $2,27,49(3)$ & $\begin{array}{l}\text { Dark coloured, appressed cultures with many } \\
\text { concentric rings evenly distributed }\end{array}$ & $2(\mathrm{P})$ \\
\hline MG 4 & $32,44,47,48(4)$ & Dark coloured but fluffy cultures with no concentric rings & $47(\mathrm{M})$ \\
\hline MG 5 & $6,8,17,21,22,39,41,45,46,50(10)$ & Dark brown, appressed cultures with faint concentric rings & $46(\mathrm{P})$ \\
\hline MG 6 & $3(1)$ & Dark coloured, appressed cultures with no concentric rings & $3(\mathrm{P})$ \\
\hline MG 7 & $33,34,35(3)$ & $\begin{array}{l}\text { White base with gray coloured top. Gray mycelium forms } \\
\text { faint concentric rings }\end{array}$ & $33(\mathrm{M})$ \\
\hline MG 8 & $40(1)$ & $\begin{array}{l}\text { Dark with gray coloured middle, fluffy with evenly } \\
\text { distributed concentric rings }\end{array}$ & $40(\mathrm{P})$ \\
\hline MG 9 & $\begin{array}{l}1,5,12,18,20,23,25,28,30,31 \\
36,37,38,42,43(15)\end{array}$ & White compact with no concentric rings & $25(\mathrm{P})$ \\
\hline
\end{tabular}

\footnotetext{
${ }^{a}$ Figures in bracket are total number of isolates comprising a morphological group.

${ }^{\mathrm{b}} \mathrm{P}$ : patchy; M: midrib; PP: pinpoint.
}

\subsection{Pathogenicity test}

On the basis of infective performance with eight selected sorghum lines (R/MR/S), the 50 isolates were separated into seven pathogenicity groups (Table 4). Pathogenicity group (PG) 4 had the highest number of isolates (11) while PGs 2 and 7 had the least five isolates each. The representative isolates from each of the seven PGs were: isolates 6, 8, 10, 15, 20, 24 and 30. Two sorghum lines IRAT 204 and BES were susceptible to all the seven isolates, while KSV 8 was highly resistant.

Table 3

Cultural and morphological characteristics of nine representative isolates of Colletotrichum sublineolum from sorghum growing areas of Nigeria

\begin{tabular}{|c|c|c|c|c|c|c|c|}
\hline \multirow[t]{2}{*}{ Group } & \multirow{2}{*}{$\begin{array}{l}\text { Growth } \\
\text { rate }(\mathrm{mm})\end{array}$} & \multirow{2}{*}{$\begin{array}{l}\text { Spore } \\
\text { count }\end{array}$} & \multicolumn{2}{|c|}{ Conidial length (mm) } & \multicolumn{2}{|c|}{ Conidial width (mm) } & \multirow{2}{*}{$\begin{array}{l}\text { Setae length } \\
(\mu \mathrm{m}) \text {, mean }\end{array}$} \\
\hline & & & Mean & Range & Mean & Range & \\
\hline MG 1 & 3.7 & 62.0 & 22.0 & $21.8-31.7$ & 9.30 & $8.0-10.4$ & 141.4 \\
\hline MG 2 & 4.3 & 104.3 & 20.98 & $20.6-21.3$ & 8.32 & $7.2-9.5$ & 151.2 \\
\hline MG 3 & 4.3 & 69.3 & 27.46 & $24.7-30.4$ & 9.20 & $8.4-10.0$ & 127.5 \\
\hline MG 4 & 3.7 & 41.7 & 24.76 & $20.4-30.7$ & 8.60 & $7.7-9.8$ & 132.1 \\
\hline MG 5 & 3.4 & 48.0 & 25.14 & $20.7-30.4$ & 9.02 & $8.7-9.9$ & 136.2 \\
\hline MG 6 & 4.3 & 41.7 & 27.76 & $24.5-30.5$ & 9.54 & $8.7-9.9$ & 119.9 \\
\hline MG 7 & 3.7 & 66.3 & 26.42 & $23.9-29.8$ & 9.00 & $8.5-9.8$ & 118.2 \\
\hline MG 8 & 3.7 & 53.7 & 24.36 & $21.1-27.8$ & 8.28 & $7.6-9.7$ & 148.0 \\
\hline MG 9 & 3.2 & 191.7 & 17.46 & $15.3-19.4$ & 4.06 & $3.0-5.2$ & 87.3 \\
\hline Mean & 3.8 & 75.41 & 24.04 & - & 8.37 & - & 129.1 \\
\hline S.E.M. & 0.1 & 5.90 & 1.42 & - & 0.34 & - & 1.7 \\
\hline $\mathrm{CV}(\%)$ & 4.0 & 13.6 & 12.90 & - & 9.00 & - & 2.9 \\
\hline Error DF & 32 & 16 & 32 & - & 32 & - & 32 \\
\hline
\end{tabular}


Table 4

Pathogenicity reaction of seven representative isolates of pathogenicity groups (PG) of Colletotrichum sublineolum on eight sorghum differential lines in a screenhouse ${ }^{\mathrm{a}}$

\begin{tabular}{llllllllll}
\hline Sorghum line & Race & Origin & PG 1 (24) & PG 2 (6) & PG 3 (10) & PG 4 (30) & PG 5 (15) & PG 6 (20) & PG 7 (8) \\
\hline IS 6958 & Durra caudatum & Sudan & S & R & MR & S & MR & S & R \\
A 226-2 & Caudatum & India & MR & R & R & MR & S & S & MR \\
IS 18442 & Guinea-durra & India & MR & MR & MR & S & S & S & S \\
IS 6928 & Kafir caudatum & India & S & R & S & S & MR & S & MR \\
IS 3758 & Caudatum bicolor & USA & S & S & S & S & S & S & MR \\
IRAT 204 & Durra caudatum & Burkina Faso & S & S & S & S & S & S & S \\
BES & Caudatum & Nigeria & S & S & S & S & S & S & S \\
KSV 8 & Caudatum & Nigeria & R & R & R & R & R & R & R \\
\hline
\end{tabular}

${ }^{a}$ R: resistant (no symptoms); MR: moderately resistant (reddening or red spots, necrosis); S: susceptible lesions with acervuli; PG 1: 7, 16, 19, 24, 26, 34, 44, 48 (8); PG 2: 6, 9, 13, 22, 39 (5); PG 3: 2, 10, 27, 32, 47, 49, 50 (7); PG 4: 12, 18, 25, 30, 31, 33, 35, 38, 40, 42, 53 (11); PG 5: 3, 4, 14, 15, 29, 45, 46 (7); PG 6: 1, 5, 20, 23, 28, 36, 37 (7); PG 7: 8, 11, 17, 21, 41 (5); the representative isolate number of each PG.

\subsection{Assessment of virulence and aggressiveness}

The reaction types and disease severity of the test isolates of MGs and PGs presented in Table 5. Disease reaction was quite variable amongst the isolates and the host lines. Isolates of MGs 7, 9 and PG 6 were the most virulent on seven of the eight lines evaluated susceptible, while isolate MG 1 was the least virulent producing symptoms on only two lines. Significant differences $(P<0.05)$ were evident among isolates and lines (Table 6). Disease severity was also highly variable amongst the isolates and lines. Aggressiveness among the isolates, measured by comparing the variation in the degree of mean disease severity on the

Table 5

Reaction class (RC) and disease severity (DS) of 16 isolates of Colletotrichum sublineolum on eight sorghum lines in a screenhouse ${ }^{\mathrm{a}}$

\begin{tabular}{|c|c|c|c|c|c|c|c|c|c|c|c|c|c|c|c|c|c|c|}
\hline \multirow[t]{3}{*}{ Isolate } & \multicolumn{16}{|c|}{ Sorghum line } & \multirow[t]{3}{*}{$\mathrm{MDS}^{\mathrm{b}}$} & \multirow[t]{3}{*}{$\mathrm{NSG}^{\mathrm{c}}$} \\
\hline & \multicolumn{2}{|c|}{ IS 6958} & \multicolumn{2}{|c|}{ A $2267-2$} & \multicolumn{2}{|c|}{ IS 18442} & \multicolumn{2}{|c|}{ IS 6928} & \multicolumn{2}{|c|}{ IS 3758} & \multicolumn{2}{|c|}{ IRAT 204} & \multicolumn{2}{|c|}{ BES } & \multicolumn{2}{|c|}{ KSV 8} & & \\
\hline & $\mathrm{RC}$ & DS & $\mathrm{RC}$ & DS & $\mathrm{RC}$ & DS & $\mathrm{RC}$ & DS & $\mathrm{RC}$ & DS & $\mathrm{RC}$ & DS & $\mathrm{RC}$ & DS & $\mathrm{RD}$ & DS & & \\
\hline MG 1 & $\mathrm{R}$ & 1.0 & MR & 2.5 & MR & 2.6 & $\mathrm{R}$ & 1.0 & MR & 2.2 & $\mathrm{~S}$ & 3.2 & $\mathrm{~S}$ & 4.3 & $\mathrm{R}$ & 1.0 & 2.2 & 2 \\
\hline MG 2 & $\mathrm{R}$ & 1.0 & MR & 2.7 & $\mathrm{~S}$ & 5.4 & $\mathrm{R}$ & 1.0 & $\mathrm{~S}$ & 4.0 & $\mathrm{~S}$ & 6.9 & $\mathrm{~S}$ & 7.2 & $\mathrm{R}$ & 1.0 & 3.7 & 4 \\
\hline MG 3 & MR & 2.0 & MR & 2.6 & MR & 2.8 & $\mathrm{R}$ & 1.0 & $\mathrm{~S}$ & 6.9 & $\mathrm{~S}$ & 6.0 & $\mathrm{~S}$ & 5.3 & $\mathrm{R}$ & 1.0 & 3.5 & 3 \\
\hline MG 4 & $\mathrm{R}$ & 1.0 & $\mathrm{R}$ & 1.0 & $\mathrm{R}$ & 1.0 & $\mathrm{R}$ & 1.0 & $\mathrm{~S}$ & 5.9 & $\mathrm{~S}$ & 5.1 & $\mathrm{~S}$ & 6.9 & $\mathrm{R}$ & 1.0 & 2.9 & 3 \\
\hline MG 5 & $\mathrm{R}$ & 1.0 & MR & 1.8 & $\mathrm{~S}$ & 5.6 & $\mathrm{R}$ & 1.0 & MR & 2.8 & $\mathrm{~S}$ & 3.9 & $\mathrm{~S}$ & 7.6 & MR & 1.2 & 3.1 & 3 \\
\hline MG 6 & MR & 2.8 & $\mathrm{~S}$ & 4.1 & $\mathrm{~S}$ & 6.4 & MR & 2.3 & $\mathrm{~S}$ & 5.1 & $\mathrm{~S}$ & 5.4 & $\mathrm{~S}$ & 6.4 & $\mathrm{R}$ & 1.0 & 4.2 & 5 \\
\hline MG 7 & $\mathrm{~S}$ & 7.1 & $\mathrm{~S}$ & 3.9 & $\mathrm{~S}$ & 7.0 & $\mathrm{~S}$ & 5.2 & $S$ & 6.0 & $\mathrm{~S}$ & 3.9 & $\mathrm{~S}$ & 7.5 & $\mathrm{R}$ & 1.0 & 5.2 & 7 \\
\hline MG 8 & $\mathrm{~S}$ & 6.7 & $\mathrm{~S}$ & 6.6 & $\mathrm{~S}$ & 5.6 & $\mathrm{~S}$ & 5.5 & MR & 2.6 & $\mathrm{~S}$ & 7.8 & $\mathrm{~S}$ & 5.4 & MR & 1.3 & 5.2 & 6 \\
\hline MG 9 & $S$ & 4.4 & $\mathrm{~S}$ & 5.4 & $S$ & 5.9 & $S$ & 4.5 & $S$ & 5.0 & $\mathrm{~S}$ & 5.8 & $S$ & 8.4 & $\mathrm{R}$ & 1.0 & 5.1 & 7 \\
\hline PG 1 & $S$ & 5.1 & MR & 1.3 & MR & 2.6 & $S$ & 4.5 & $S$ & 5.3 & $\mathrm{~S}$ & 6.9 & $\mathrm{~S}$ & 7.4 & $\mathrm{R}$ & 1.0 & 4.3 & 5 \\
\hline PG 2 & $\mathrm{R}$ & 1.0 & $\mathrm{R}$ & 1.0 & MR & 2.1 & $\mathrm{R}$ & 1.0 & $S$ & 4.7 & $\mathrm{~S}$ & 5.3 & $\mathrm{~S}$ & 5.4 & $\mathrm{R}$ & 1.0 & 2.7 & 3 \\
\hline PG 3 & MR & 1.4 & $\mathrm{R}$ & 1.0 & MR & 1.3 & $\mathrm{~S}$ & 5.3 & $\mathrm{~S}$ & 5.1 & $\mathrm{~S}$ & 6.2 & $\mathrm{~S}$ & 6.3 & $\mathrm{R}$ & 1.0 & 3.5 & 4 \\
\hline PG 4 & $\mathrm{~S}$ & 4.7 & MR & 1.3 & S & 5.0 & $\mathrm{~S}$ & 5.1 & $S$ & 5.2 & $\mathrm{~S}$ & 6.1 & $S$ & 8.6 & $\mathrm{R}$ & 1.0 & 4.6 & 6 \\
\hline PG 5 & MR & 1.2 & $\mathrm{~S}$ & 4.1 & $\mathrm{~S}$ & 4.2 & MR & 2.4 & $S$ & 4.3 & $\mathrm{~S}$ & 5.8 & $\mathrm{~S}$ & 6.0 & $\mathrm{R}$ & 1.0 & 3.6 & 5 \\
\hline PG 6 & $\mathrm{~S}$ & 7.0 & $\mathrm{~S}$ & 3.8 & $\mathrm{~S}$ & 5.0 & $\mathrm{~S}$ & 4.1 & $\mathrm{~S}$ & 4.8 & $\mathrm{~S}$ & 6.2 & $\mathrm{~S}$ & 8.0 & $\mathrm{R}$ & 1.0 & 5.0 & 7 \\
\hline PG 7 & $\mathrm{R}$ & 1.0 & MR & 1.2 & $\mathrm{~S}$ & 4.6 & MR & 2.1 & MR & 2.9 & $\mathrm{~S}$ & 6.1 & $S$ & 7.6 & $\mathrm{R}$ & 1.0 & 3.3 & 3 \\
\hline Mean & & 3.0 & & 2.8 & & 4.2 & & 2.9 & & 4.6 & & 5.7 & & 6.8 & & 1.0 & & \\
\hline
\end{tabular}

${ }^{a}$ Each value represents the mean of 15 replications (five replications per repetition).

${ }^{\mathrm{b}}$ Mean disease severity of an isolate on eight genotypes.

${ }^{c}$ Number of lines showing susceptible reaction to each isolate. 
Table 6

Analysis of variance for disease severity of 16 isolates of Colletotrichum sublineolum on eight sorghum lines grown in a screenhouse

\begin{tabular}{lrcl}
\hline Source of variation & DF & Mean square & $F$-value \\
\hline Replications & 4 & 0.194 & 0.03 \\
Isolates & 15 & 9.664 & $1.67^{* *}$ \\
Sorghum genotypes & 7 & 26.864 & $4.64^{* *}$ \\
Isolates $\times$ sorghum genotypes & 105 & 4.096 & \\
Residual (error) & 508 & 5.785 & \\
\hline
\end{tabular}

two sorghum genotypes (BES, IRAT 204) that were susceptible to all 16 isolates. Isolates of PGs 1, 4, 6, and MGs 2 and 9 were identified as most aggressive while isolate MG 1 was the least aggressive (Table 7).

Cluster analysis of 16 representative MG and PG isolates categorised them into five groups (Fig. 2). Group 1 comprised of Isolates MGs 1, 3, 4, 5 and PGs 3 and 7 that caused S reaction on BES and IRAT 204; $\mathrm{R}$ or MR reaction on KSV 8, IS 6928, IS 6958 and A2267-2, and were identified as least virulent. Group 2 , which comprised a single isolate from MG 2, caused $\mathrm{S}$ reaction on four lines (IS 18442, IS 3758, IRAT 204 and BES) and R reaction in KSV 8, IS 6928 and IS 6958. Group 3 also comprised a single isolate, in this case from PG 2, caused S reaction in three lines (IS 3758, IRAT 204, BES) and R in KVS 8 and IS 6928. Group 4 included isolates of MG 6 and PGs 1 and 5, that caused $\mathrm{S}$ reaction in five lines and $\mathrm{R}$ in one $(\mathrm{KSV}$
Table 7

Relative aggressiveness of 16 isolates of Colletotrichum sublineolum as measured by disease severity on two susceptible sorghum lines in a screenhouse

\begin{tabular}{llll}
\hline Isolate & \multicolumn{2}{l}{ Disease severity } & \\
\cline { 2 - 4 } & IRAT 204 & BES & Mean $^{\mathrm{a}}$ \\
\hline MG 1 & 3.2 & 4.3 & 3.8 \\
MG 2 & 6.9 & 7.2 & 7.1 \\
MG 3 & 6.0 & 5.3 & 5.7 \\
MG 4 & 5.1 & 6.9 & 6.0 \\
MG 5 & 3.9 & 7.6 & 5.8 \\
MG 6 & 5.4 & 6.4 & 5.9 \\
MG 7 & 3.9 & 7.5 & 5.7 \\
MG 8 & 7.8 & 5.4 & 6.6 \\
MG 9 & 5.8 & 8.4 & 7.1 \\
PG 1 & 6.9 & 7.4 & 7.2 \\
PG 2 & 5.3 & 5.4 & 5.4 \\
PG 3 & 6.2 & 6.3 & 6.3 \\
PG 4 & 6.1 & 8.6 & 7.4 \\
PG 5 & 5.1 & 6.0 & 5.6 \\
PG 6 & 6.2 & 8.0 & 7.1 \\
PG 7 & 6.1 & 7.6 & 6.9 \\
Mean & 5.7 & 6.8 & \\
\hline
\end{tabular}

${ }^{a}$ High mean value indicates high aggressiveness level of isolate.

8). Group 5 included isolates of MGs 7, 8 and 9, and PGs 4 and 6 causing $S$ reaction in six lines and $R$ reaction in two lines (KSV 8, IS 6958). Group 5 was identified as most virulent group.
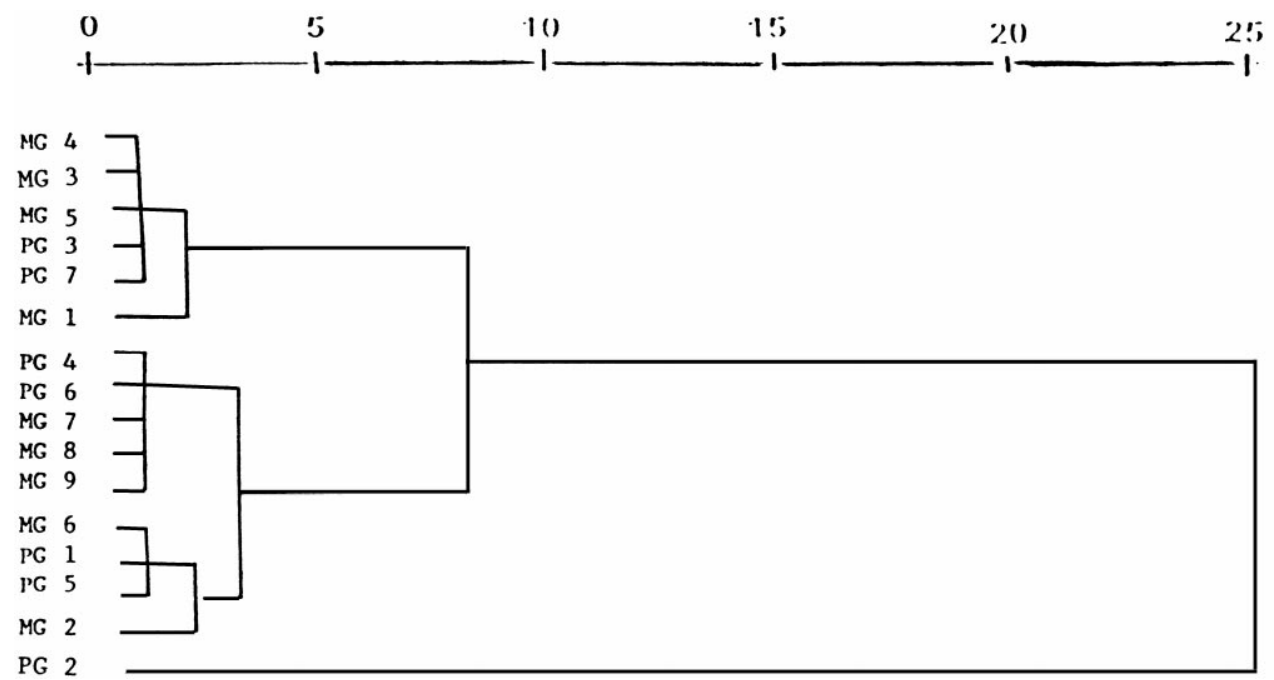

Fig. 2. Dendrogram showing the clustering of the nine morphological and seven pathogenic groups of Colletotrichum sublineolum isolates into five physiologic races. 


\section{Discussion}

The 50 isolates of $C$. sublineolum collected from major sorghum growing areas of Nigeria showed considerable variation in cultural, morphological and pathogenic characteristics. Using cultural and morphological characteristics, we established nine groups among the isolates; while on the basis of pathogenicity, seven distinct groups were identified. This evidence of physiological races within $C$. sublineolum population supports earlier work in Nigeria by Ozolua et al. (1986). Reports by Ali and Warren (1987), Cardwell et al. (1989), Ferreira et al. (1985) and Pande et al. (1991) have variously shown the existence of variation among foliar anthracnose isolates in other parts of the world. A recent report by Thakur and Rao (1998) based on the results of ISAVN from 1992 to 1997 also indicated the existence of variation among populations of the pathogen in the different parts of the world. It is desirable to compare between isolate groupings identified in this study with those by other workers, e.g. Ali and Warren (1987), Pande et al. (1991) from other parts of the world, but to do so using standard differential lines. There is the need to identify an international set of differentials (e.g. using the ISAVN set) for use by future workers to enable evaluation of populations and establishment of race groups as in other pathogens, e.g. Spacelotheca sorghi (Frowd, 1980).

MG 9 and PG 6 were identified as the most virulent isolates in this study. None of the 16 selected MG or PG isolates induced an MR reaction with a high disease severity. Pande et al. (1991) also reported that in the hypersensitive reaction (HR), chlorotic flecks did not enlarge and sometimes disappeared 7 days after inoculation. It may therefore not be possible to have resistant phenotypes with a high disease severity rating. The level of aggressiveness was observed to vary among the isolates within groups and did not directly correlate with virulence. Isolates MG 7 and MG 8 were more aggressive than others. Pande et al. (1991) ascribed the differential relationship between virulence and aggressiveness or degree of pathogenicity as observed in this trial to isolate-host genotypic interaction. However, when mean disease severity on the two most susceptible cultivars was used (Table 7), virulence in isolates MG 9 and PG 6 correlated positively with aggressiveness. Because isolates in these two groups were both widely infective and caused highest level of disease severity, they may be the most widespread and damaging in Nigeria.

Cluster analysis of disease severity data obtained for the 16 isolates show that they belong to five distinct classes or physiologic races. Alawode et al. (1983) proposed three races, based on symptom type, but the results of this study show that isolates obtained from pinpoint lesion isolates (MG 9 in Table 2) are not distinctly different from those obtained from leaves exhibiting patchy or midrib symptoms. Isolates from pinpoint lesions had similar cultural and morphological characteristics to other isolates in this group. This supports an earlier report by Bindawa (1987), who indicated that isolates from patchy and pinpoint lesions differed only on the basis of symptom expression. Thus, there may be only five physiologic races of the pathogen present on leaves of sorghum in Nigeria. An on-going study is examining the variability of the pathogen in isolates obtained from different plant parts and may add to the number of races obtained from the current study. With increasingly diverse sorghum cultivars in use, and as the makeup of populations of $C$. sublineolum changes, appearance of new races is likely. There is therefore an apparent need to routinely monitor and study the make up of the pathogen population through virulence surveys over time. As the existence of races among pathogen populations present challenging problems to breeders and pathologists trying to develop resistant cultivars, efforts to identify sources of resistance to new races should receive priority in order to breed resistant cultivars of sorghum. It is expected that the results of this study will contribute to on-going breeding programmes targeted at reducing the rate of disease development with all races. This has been achieved for KSV 8 which is resistant to anthracnose and high yielding. It has since been released to Nigerian farmers as SAMAORG 14 (Aliyu et al., 1996).

\section{Acknowledgements}

We acknowledge technical assistance by Messrs Abdulrahman Ahmed and Titus Ochibe and thank Messrs D. Jarma and Y. Otitoju for statistical analysis. We are grateful to J.W. Stenhouse and R. Bandyopadhyay, ICRISAT, Patancheru, India for facilitating 
funding the position of a Visiting Scientist which enabled this work to be carried out, and the Director, IAR for permission to undertake the assignment.

\section{References}

Alawode, D.A., Manzo, S.K., Sundaram, N.V., 1983. Anthracnose of sorghum in Nigeria. In: Proceedings of the Paper Presented at the 13th Annual Conference of the Nigerian Society for Plant Protection at Plant Quarantine Station, Moor Plantation, Ibadan, 7-10 March 1983.

Ali, M.E.K., Warren, H.L., 1987. Physiological races of Colletotrichum graminicola on sorghum. Plant Dis. 71, 402-404.

Aliyu, A., Odegbaro, O.A., Ayeni, F.J., 1996. Directory of Commercializable Research Findings of Nigerian Agricultural Research Institutes, Vol. 1. National Agricultural Research Project (NARP), Department of Agricultural Sciences, Federal Ministry of Agriculture and Natural Resources, $89 \mathrm{pp}$.

Bindawa, A.A., 1987. Studies on anthracnose of sorghum and maize caused by Colletotrichum graminicola (Ces). Wils. and on a midrib spot on millet. M.Sc. Thesis, Ahmadu Bello University, Zaria, Nigeria, $67 \mathrm{pp}$.

Cardwell, K.F., Hepperly, P.R., Frederiksen, R.A., 1989. Pathotypes of Colletotichum graminicola and seed transmission of sorghum anthracnose. Plant Dis. 73, 255-257.

Ferreira, A.D.S., Frederiksen, R.A., Warren, H., De Castillo, K.C., 1985. Identification of races of Colletotrichum graminicola in Brazil. Sorghum Newslett. 28, 80-83.

Frowd, J.A., 1980. A world review of sorghum smuts. In: Sorghum diseases, a world review. Proceedings of the International Workshop on Sorghum Diseases, 11-15 December 1978, ICRISAT, Hyderabad, India. International Crops Research Institute for the Semi-Arid Tropics, Patancheru, Andhra Pradesh 502 324, India, p. 331-338.

King, S.B., Frederiksen, R.A., 1976. Report on the international sorghum anthracnose virulence nursery. Sorghum Newslett. 19, 105-106.

Manzo, S.K., 1985. Sorghum pathology. Cropping Scheme Meeting Report, Cereals Research Programme, IAR, ABU, Zaria.

Marley, P.S., 1996a. Report on Survey for Prevalence of Panicle Anthracnose in Nigeria, 1996, 8 pp (limited distribution).

Marley, P.S., 1996b. Sorghum pathology. Institute for Agricultural Research Cropping Scheme Meeting, Report on Cereals Research Programme, 1996.

NAERLS, 1996. Prospects and problems of the 1996 cropping season. A report of study conducted by National Agricultural
Extension and Rural Liaison Services (NAERLS) and Agricultural Planning Monitoring and Evaluation Unit (APMEU) between 20 September and 4 October 1996. NAERLS, Ahmadu Bello University, Samaru, Zaria, Nigeria, 1996.

Norman, H.N., Hull, C.H., Jenkins, J.G., Steinbrenner, K., Bent, D.H., 1984. Statistical Package for the Social Sciences. McGraw-Hill, New York, 675 pp.

Ozolua, K.O.O., Tyagi, P.D., Emechebe, A.M., 1986. Pathogenic variation in Colletotrichum graminicola, the causal agent of anthracnose of sorghum in Nigeria. Samaru J. Agric. Res. 4, 79-84.

Pastor-Corrales, M.A., Frederiksen, R.A., 1980. Sorghum anthracnose. In: Sorghum diseases: a world review. Proceedings of International Workshop on Sorghum Diseases, 1978, Hyderabad, India, ICRISAT, pp. 289-291.

Pande, S., Mughogbo, L.K., Bandyopadhyay, R., Karunakar, R.I., 1991. Variation in pathogenicity and cultural characteristics of sorghum isolates of Colletotrichum graminicola in India. Plant Dis. $75,778-783$.

Pande, S., Harikrishnan, R., Alegbejo, M.D., Mughogho, L.K., Krunakar, R.I., Ajayi, O., 1993. Prevalence of sorghum diseases in Nigeria. Int. J. Pest Man. 39 (3), 297-303.

Tarr, S.A.J., 1962. Diseases of Sorghum, Sudangrass and Broom Corn. Commonwealth Mycological Institute, Kew, Surrey, UK, $380 \mathrm{pp}$.

Thakur, R.P., 1995. Status of international sorghum anthracnose and pearl millet downy mildew virulence nurseries. In: Leslie, J.F., Frederiksen, R.A. (Eds.), Disease Analysis through Genetics and Biotechnology - Interdisciplinary Bridges to Improve Sorghum and Millet Crops. IOWA State University Press, Ames, pp. 75-92.

Thakur, R.P., Rao, V.P., 1998. International Sorghum Anthracnose Virulence Nursery (ISAVN). A Summary Report (1992-1997). Genetic Resource Enhancement Program, International Crops Research Institute for the Semi-Arid Tropics (ICRISAT), Patancheru 502324, Andhra Pradesh, India.

Thomas, M.D., 1995. Sorghum anthracnose research in West Africa: a look at the present and the future. In: Leslie, J.F., Frederiksen, R.A. (Eds.), Diseases Analysis through Genetics and Biotechnology - Interdisciplinary Bridges to Improve Sorghum and Millet Crops. IOWA University Press, Ames, pp. $127-136$.

Tyagi, P.D., 1980. Sorghum diseases in Nigeria. In: Sorghum diseases: a world review. Proceedings of International Workshop on Sorghum Diseases, 11-15 December 1978, Hyderabad, India.

Zummo, N., 1984. Sorghum diseases in Western Africa. Washington, DC, 20250, USDA, USAID, USA, 32 pp. 